DOI: $10,4046 / \operatorname{trd} 2010,68,5,290$

ISSN: 1738-3536(Print)/2005-6184(Online)

Tuberc Respir Dis 2010;68:290-293

Copyright(C)2010. The Korean Academy of Tuberculosis and Respiratory Diseases. All rights reserved.

\title{
Prostatic Cancer Presenting as an Isolated Large Lung Mass
}

Hee Sun No, M.D. ${ }^{1}$, Jong Hwan Lee, M.D. ${ }^{1}$, Young Ahn, M.D. ${ }^{1}$, Im II Na, M.D. ${ }^{1}$, Hye-Ryoun Kim, M.D. ${ }^{1}$, Cheol Hyeon Kim, M.D. ${ }^{1}$, Jae Soo Koh, M.D. ${ }^{2}$, Jae Cheol Lee, M.D.

Departments of ${ }^{1}$ Internal Medicine, ${ }^{2}$ Pathology, Korea Cancer Center Hospital, Seoul, Korea

A hidden primary tumor presenting as an isolated lung mass is a diagnostic challenge to physicians because the diagnosis of lung cancer is likely to be made if the histologic findings are not inconsistent with lung cancer. A large lung mass was found incidentally in a 59-year-old man. Although adenocarcinoma was diagnosed by percutaneous needle biopsy, thyroid transcription factor-1 (TTF-1) immunostaining was negative, raising suspicion that there was another primary site. There was no abnormal finding except for the lung mass on a ${ }^{18}$ FDG-PET/CT scan and the patient did not complain of any discomfort. Finally, prostatic cancer was confirmed through the study of tumor markers and prostate-specific antigen (PSA) immunostaining. Because of the rare presentation of a single lung mass in malignancies that have another primary site, physicians should carefully review all data before making a final diagnosis of lung cancer.

Key Words: Metastasis; Prostatic Neoplasms; Thyroid Transcription Factor 1; Tumor Markers, Biological

\section{Introduction}

Prostatic cancer is the most common cancer of men in western countries ${ }^{1}$ while its incidence and mortality in Asia were estimated to be quite lower although there has been a recent trend towards increasing incidence of prostate cancer in that area ${ }^{2}$. Bones such as pelvis, femur, spines and ribs are frequently involved by hematogenous metastasis through venous plexus of Batson ${ }^{3}$. Pulmonary metastasis is also not uncommon ${ }^{4}$.

Symptoms from prostatic cancer are rarely present at the time of diagnosis in most patients. Therefore, it was often detected due to problems of metastatic site ${ }^{5}$. In addition, because presenting features of prostatic cancer are sometimes very unusual, there is the risk of wrong diagnosis. Here, we report a patient with prostatic cancer presenting as isolated large lung mass. Because ini-

Address for correspondence: Jae Cheol Lee, M.D.

Department of Internal Medicine, Korea Cancer Center Hospital, 215-4, Gongneung-dong, Nowon-gu, Seoul 139-

706, Korea

Phone: 82-2-970-1206, Fax: 82-2-970-2438

E-mail: jclee@kcch.re.kr

Received: Dec. 14, 2009

Accepted: Dec. 30, 2009 tially, there were no diagnostic clues suggesting the primary site, it almost mimicked the primary lung cancer.

\section{Case Report}

A large left upper lung mass was incidentally found on chest radiograph in a 59-year-old man with no history of smoking (Figure 1A). He was previously healthy and did not present any specific symptoms related with respiratory, gastro-intestinal, skeletal and genitor-urinary systems. A $9.4 \mathrm{~cm}$-sized mass along posterior pleural surface in the left upper lobe without any enlarged mediastinal lymph node was found on chest computed tomography (CT) (Figure 1B). ${ }^{18}$ F-FDG PET revealed hypermetabolic lesions in lung, abdominal lymph nodes and multiple bones (Figure 1C). Extensive bone metastasis was also confirmed by a bone scan (Figure 1D). However, there was no abnormal uptake in other organs including the gastro-intestinal and genitor-urinary tracts. A sample of the lung mass was obtained by percutaneous needle aspiration biopsy. Pathologic examination revealed adenocarcinoma (Figure 2A). Although the diagnosis of lung cancer with multiple metastases was probable, we decided to check tumor markers to 

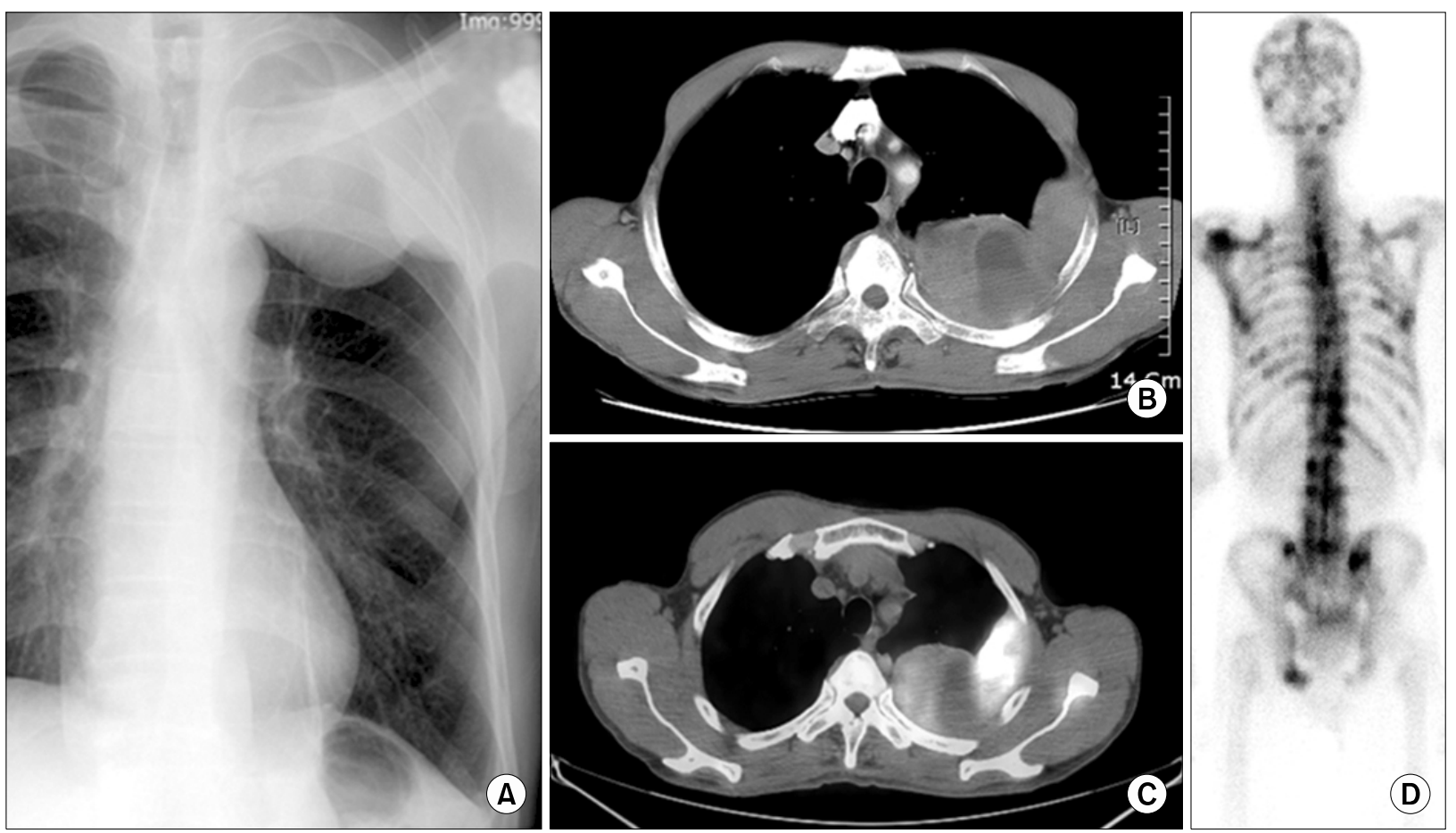

Figure 1. (A) Chest radiograph showed a large lung mass on left upper lung. (B) A lung mass with central necrosis along posterior pleural surface was noted on chest CT. (C) Uneven ${ }^{18} \mathrm{FDG}$ uptake of the lung mass was revealed on PET/CT. (D) Bone scan showed multiple metastatic bony lesions.

rule out lung metastasis from other primary cancers because the immunostaining for thyroid transcription factor-1 (TTF-1) was negative (Figure 2B). Unexpectedly, the serum PSA level was high $(5148.0 \mathrm{ng} / \mathrm{mL}$; normal range, $0 \sim 4 \mathrm{ng} / \mathrm{mL}$ ), raising the possibility of prostatic cancer. A prostatic mass was detected by ultrasound and a trans-rectal biopsy was done. Pathologic examination of the specimen showed adenocarcinoma with a Gleason score $4+5$, which involved 11 of the 12 cores taken from the prostate (Figure 2C). Lung and prostate tissues displayed the same morphology and were both positive for PSA immmunostaining, leading to the final diagnosis of prostate cancer with multiple metastases (Figure 2D). Therapy with luteinizing hormone-releasing hormone agonist $(3.6 \mathrm{mg}$, once monthly, subcutaneous injection) was started. A follow-up examination with chest radiography and CT after 1 month showed that the lung lesion had markedly decreased in size (Figure 3). Serum PSA level had also decreased to 143.9 $\mathrm{ng} / \mathrm{mL}$.

\section{Discussion}

This report clearly showed that physicians should be very cautious before making a diagnosis of lung cancer because of rare presentation as a lung mass in other site malignancy. Hence, it is required to carefully review all data before final diagnosis for discovery of something unusual in lung cancer, especially, with adenocarcinoma histology because the primary adenocarcinoma can be more silently present inside body. Adenocarcinoma has become the most common histology of lung cancer accounting for more than $30 \%$, It is expected that the proportion of adenocarcinoma would continue to increase. Moreover, recent use of low-dose spiral CT for lung cancer screening would detect more metastasis of other hidden primary cancer to lung including early, isolated lesion in addition to early lung cancer ${ }^{8,9}$. Therefore, there would be more chances for physicians to encounter patients like our case reported here. 
HS No et al: Prostatic cancer presenting as a lung mass
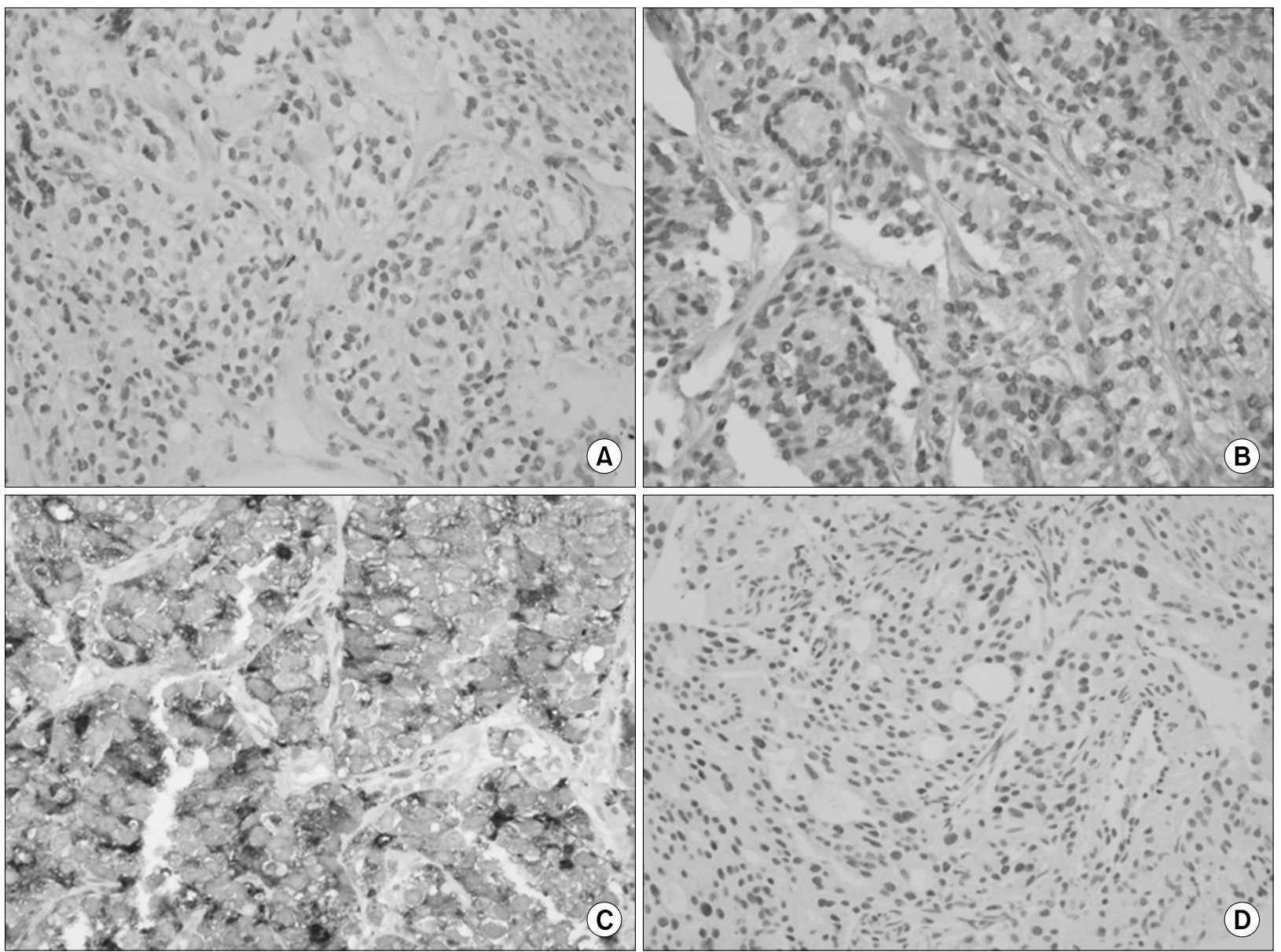

Figure 2. (A) Adenocarcinoma was diagnosed by percutaneous needle biopsy from lung tumor (H\&E stain, $\times 200)$. (B) TTF-1 immunostaining of lung tumor was negative (TTF-1 immunostain, $\times 200$ ). (C) PSA immunostaining of lung tumor tissues was strong positive (PSA immunostain, $\times 400)$. (D) Prostatic biopsy showed almost same morphologic features with lung tumor (H\&E stain, $\times 200)$.
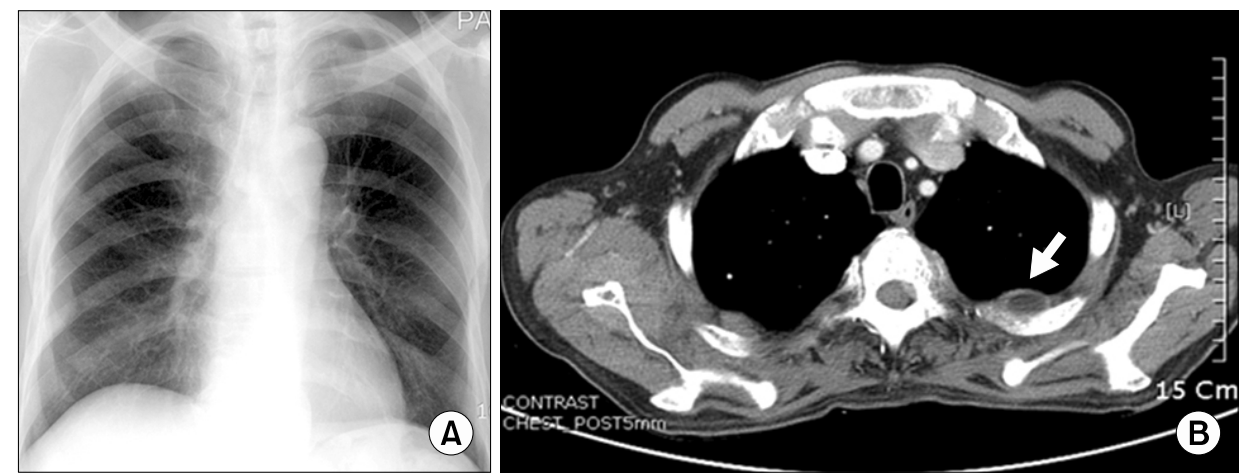

Figure 3. (A) The size of huge lung mass was markedly reduced by treatment with a luteinizing hormone-releasing hormone agonist on chest radiograph. (B) Chest CT also showed the shrunken mass with necrosis (arrow).

We performed TTF-1 immunostaining because we thought it is not common for lung cancer to metastasize to multiple bones and abdominal lymph nodes without mediastinal involvement. In addition, the differentiation from malignant pleural mesothelioma was also needed because the tumor mass broadly contacted with pleura 
surface, and because malignant pleural mesothelioma and peripheral adenocarcinoma of the lung often show similar clinical and radiological characteristics and even similar microscopic findings ${ }^{10,11}$. TTF-1 immunostaining is a very sensitive and specific method in the differential diagnosis of primary and metastatic lung adenocarcinoma $^{12}$ and also can be useful to exclude mesothelioma ${ }^{13}$. It helped us in the search for another primary site of cancer.

Should TTF-1 immunostaining be routinely done before diagnosis of lung adenocarcinoma? It is a quite controversial question although the procedure can be done easily and without substantial cost and it would help to lessen the already-low risk of embarking on the wrong treatment. More accumulation of clinical experiences about hidden adenocarcinoma presenting a lung mass seems to be able to answer it.

\section{References}

1. Jemal A, Siegel R, Ward E, Murray T, Xu J, Thun MJ. Cancer statistics, 2007. CA Cancer J Clin 2007;57:43-66.

2. Sim HG, Cheng CW. Changing demography of prostate cancer in Asia. Eur J Cancer 2005;41:834-45.

3. Bubendorf L, Schöpfer A, Wagner U, Sauter G, Moch $\mathrm{H}$, Willi N, et al. Metastatic patterns of prostate cancer: an autopsy study of 1,589 patients. Hum Pathol 2000; 31:578-83.

4. Fabozzi SJ, Schellhammer PF, el-Mahdi AM. Pulmonary metastases from prostate cancer. Cancer 1995;75:27069.
5. Zelefsky MJ, Eastham JA, Sartor OA, Kantoff P. Chapter 40. Cancers of the genitourinary system. In: Devita VT Jr, Lawrence TS, Rosenberg SA, editors. Cancer: principles and practice of oncology. 8th ed. Philadelphia: Lippincott Williams \& Wilkins; 2008. p. 1392-462.

6. Travis WD, Travis LB, Devesa SS. Lung cancer. Cancer 1995;75:191-202.

7. Devesa SS, Bray F, Vizcaino AP, Parkin DM. International lung cancer trends by histologic type: male:female differences diminishing and adenocarcinoma rates rising. Int J Cancer 2005;117:294-9.

8. Yamada T, Ono S, Tsuboi M, Saito H, Sato A, Matsuhashi $\mathrm{T}$, et al. Low-dose CT of the thorax in cancer follow-up. Eur J Radiol 2004;51:169-74.

9. Weng MJ, Wu MT, Pan HB, Kan YY, Yang CF. The feasibility of low-dose CT for pulmonary metastasis in patients with primary gynecologic malignancy. Clin Imaging 2004;28:408-14.

10. King JE, Thatcher N, Pickering CA, Hasleton PS. Sensitivity and specificity of immunohistochemical markers used in the diagnosis of epithelioid mesothelioma: a detailed systematic analysis using published data. Histopathology 2006; 48:223-32.

11. Choi YH, Park KY, Ryoo BY, Na, II, Yang SH, Koh JS, et al. Presence of malignant mesothelial cells in the sputum. Intern Med 2008;47:57-60.

12. Moldvay J, Jackel M, Bogos K, Soltész I, Agócs L, Kovács G, et al. The role of TTF-1 in differentiating primary and metastatic lung adenocarcinomas. Pathol Oncol Res 2004;10:85-8.

13. Abutaily AS, Addis BJ, Roche WR. Immunohistochemistry in the distinction between malignant mesothelioma and pulmonary adenocarcinoma: a critical evaluation of new antibodies. J Clin Pathol 2002;55:662-8. 